\title{
KNOWLEDGE AND AWARENESS LEVEL OF THE SOCIETY ABOUT COVID-19 IN TURKEY: A CROSS SECTIONAL RESEARCH
}

\author{
Ramazan Kıraç ${ }^{1}$, Sait Söyler ${ }^{2}$ and Doğancan Çavmak ${ }^{3}$ \\ ${ }^{1}$ Health Management Department, Kahramanmaras Sutcu Imam University, Kahramanmaras, Turkey \\ ${ }^{2}$ Vocational School of Healthcare Services, Tarsus University, Mersin, Turkey. \\ ${ }^{3}$ Vocational School of Healthcare Services, Tarsus University, Mersin, Turkey.
}

Correspondence author: Doğancan Çavmak.

Email: dogancavmak@tarsus.edu.tr

\begin{abstract}
COVID-19 is a newly discovered type of virus. It is known that the disease is transmitted by droplets. The best way of protection from COVID-19 is social isolation and high level of knowledge and awareness. The study aims to determine knowledge and awareness level of the Turkish society about COVID-19. The study is cross-sectional and quantitative which conducted in Turkey's six largest cities. An online questionnaire survey was conducted to collect data. A total of 970 respondents were included in the study. The general knowledge and awareness level of the respondents was found $81 \%$. It was determined that knowledge and awareness scores significantly differed across gender. The groups with higher education gave significantly higher correct answers regarding the new type of coronavirus. It was found that the knowledge and awareness level of women about new type of coronavirus was significantly higher than men. Countries around the world have been making great efforts to stop the spread of the virus. There are many measures implemented for this purpose. However, general level of knowledge regarding COVID-19 is critical to implementing the measures and preventing infection. Therefore, the studies on population to detect knowledge level is important for decision making. In this study, it was determined that COVID-19 knowledge and awareness levels of men, people with low education level and the respondents who prefer television as a channel of obtaining information were low compared to the other groups. Therefore, it is recommended to increase awareness raising activities especially for these groups.
\end{abstract}

Keywords: Coronavirus, COVID-19, Knowledge, Awareness, Turkey

\section{INTRODUCTION}

The virus that first detected in Wuhan, the capital of China's Hubei region, has spread worldwide since the day it was detected and was declared as a pandemic. Corona virus disease, called COVID19 , is a newly discovered type of infectious disease. It has been reported that an undiscovered coronavirus has been encountered in China as a result of the examination of a group of viral pneumonia patients whose etiology is not fully known. ${ }^{1}$ Coronavirus is a large family that can cause a variety of diseases, from common cold to the known as Middle East Respiratory Syndrome (MERS-CoV) and Severe Acute Respiratory Syndrome (SARS). However, although COVID-19 emerging in China is assumed to be similar to the SARS, it has been found to be largely different from SARS-COV as a result of the genetic analysis performed. ${ }^{2}$ The common symptoms and clinical findings of COVID-19 patients are generally defined as fever, cough and difficulty in breathing. In more severe cases, it has been reported that the virus affects the central nervous system, people lose their sense of smell, and therefore the symptom of respiratory difficulty occurs. Although mild clinical symptoms are encountered in the majority of cases caused by coronavirus, it has been reported that some patients experience multiple organ failures and severe pneumonia. As a result of the analyzes carried out on the rapidly spreading cases in
China, the mortality rate of the patients with chronic diseases such as diabetes, blood pressure, heart disease and respiratory distress is determined to be at least five times higher. ${ }^{3}$

As expressed by the World Health Organization, the best way to prevent disease and avoid infection is to be informed about COVID-19 and its spread. It is especially important to wash hands or use alcohol-based disinfectants and not to touch the face. It is known that the disease is transmitted by droplets and there should be sensitivity in this regard. ${ }^{4}$ It is also known as another spread method that people in contact with contaminated surfaces touch their own faces. The incubation period of the virus is assumed to be 2 and 14 days and lasts an average of 5 days. Standard diagnosis in cases with the symptoms of the virus is made through tests performed simultaneously with the throat swab taken from the individual. In addition to tests, CT scans indicating infection symptoms and pneumonia are also evaluated. There is currently no known vaccine or cure. ${ }^{5}$ It is known that clinical research on vaccination and medicine continues. ${ }^{6}$

Knowledge and awareness level of the society related to infectious diseases is important for the prevention of outbreaks. It is emphasized that the best way of protection from COVID-19 is social isolation and high level of knowledge and awareness. Among the recommended measures 
against coronavirus are frequent hand washing, maintaining social distance, isolation, using alcohol-based hand cleaning products, covering the mouth and nose with disposable tissues while coughing and sneezing or properly covering the mouth with the inside of the elbow, and keeping hands away from the face. In addition, individuals who are required to be outside and use public transportation should clean their hands with water, soap or alcohol based disinfectants and shouldn't touch their mouths and eyes with the assumption that the virus lives for a long time on the surfaces where more than one person may touch, especially on metal surfaces. ${ }^{7}$

The measures such as suspending domestic and international travels for a while, paying attention to hygiene rules (washing hands, avoiding facetouching, using disinfectant, etc.) when traveling is mandatory, putting at least 1 meter distance from other individuals, staying away from the environments crowded with patients (health facilities, etc.) and areas such as farms and animal markets, using medical masks, avoiding eating raw or undercooked animal products and following the quarantine rules for 14 days after travel should be taken. ${ }^{8}$

Since COVID-19 is a new and therefore unknown virus type, it is necessary to increase the level of knowledge and awareness on this issue in order to prevent its spread. To the best of our knowledge, the studies carried out on COVID-19 are still very few. ${ }^{9}$ However, current studies show that improper information about COVID-19 has spread and has been adopted by the society, even in developed countries. ${ }^{10}$ In addition, it has been determined in some studies that not having access to reliable information or having insufficient level of knowledge increases anxiety level of the society. ${ }^{11,12}$

We believe that the current knowledge level of the society must be determined for an accurate informing study. In line with this conceptual framework, the aim of the study is to determine the knowledge and awareness level of Turkish society on COVID-19 and to evaluate the respondents according to their demographic characteristics.

\section{METHODS}

This cross-sectional and qualitative study was conducted using a questionnaire form developed by the researchers according to literature and expert opinions.

\section{Participants}

Relying on the researchers' network, the population over the age of 18 in Istanbul, Ankara, Izmir, Mersin, Adana and Antalya provinces, which are Turkey's sixth-largest cities, was selected as the target. The inclusion criteria for participants were being 18 age and over, literate, having internet connection, volunteering to participate in the study. The participant who are not eligible for mentioned criteria and those who did not fill the questionnaire properly were excluded.

The population over 18 age in these cities is 25.518.718 for 2020. The sample size was calculated via the following formula:

$$
\mathrm{n}=\frac{\mathrm{n}_{0}=\frac{\mathrm{Z}^{2} \times(\mathrm{p}) \times(1-\mathrm{p})}{1+\frac{\mathrm{n}_{0}}{\text { population }}}}{\mathrm{n}_{0}-1}
$$

$Z=1.96$ for $\% 95$ confidence level

$\mathrm{P}=$ percentage picking a choice

$\mathrm{C}=$ confidence interval (.05 for the study)

The sample size was calculated as 384 participants with \%95 confidence level and 5 confidence intervals. We distributed the questionnaire via e-mail to people in targeted cities and expanded by means of snowball sampling. We searched for e-mails of potential participants by investigating the websites of universities, public institutions, some private companies. We asked them to share the survey with their colleagues and networks. Also, the questionnaire distributed by author's network. We asked people who live in target cities to participate the study. We cannot obtain an e-mail list. Therefore, data collection was mostly based on researchers' network. There may be some participants from other provinces. However, all fulfilled and eligible questionnaires were included the study. Since it was not feasible to conduct a face-to-face survey with individuals because of the extraordinary conditions and lockdown, the questionnaire formed on the online platform "Google Forms" was sent to the participants. The data was collected for a week. A total of 970 respondents were included in the study.

\section{Measures}

The questionnaire form is consisted of two parts. The first part includes questions about the demographic characteristics of the participants, and the second part includes questions for determining the knowledge and awareness about COVID-19. The second part was designed based on guidelines of Turkish Ministry of Health ${ }^{7}$, World Health Organization ${ }^{13}$ and the American Center for Disease Control and Prevention-CDC ${ }^{5}$. There are 23 questions in this part. Each question was asked to be answered as Yes-No- I don't know.

The data collection tool is a survey, not a scale. Therefore, the statistical reliability and validity analyzes are not suitable. However, we conducted a content validity process. The statements created based on the mentioned studies were 
evaluated by experts who study on healthcare management in terms of clarity, relevance and simplicity. The experts rated each statement on a four-point scale. The results indicated that all statements have content validity index above 0.70 which refers to acceptable threshold. Then, a pilot study was conducted with 40 participants. According to feedbacks from participants, the statements revised and the final survey was shaped.

\section{Statistical Analysis}

The data were subjected to frequency, percentage and chi-square analyses. The demographic characteristics of the respondents and the accuracy rates of the answers given to the questions were determined as frequency and percentages. The total scores of knowledge and awareness levels were calculated by dividing the total correct answers by total answers. The total scores categorized into three. The scores under $35 \%$ refers to low, scores between $35-70 \%$ refers to medium, while above $70 \%$ is high level of knowledge and awareness. Knowledge and awareness score of participants according to demographic characteristics were compared with
Chi-square test. "The chi-squared test of independence is a widely used nonparametric test that determines an association between two categorical variables"14 The variables we examined are categorical. Therefore, we conducted a Chi-square test. The data were analyzed using SPSS version 21.0.

\section{Ethical Approval}

The protocol for this study was approved by Tarsus University Scientific Research and Publication Ethics Committee with the 2020/18 numbered decision on 07.04.2020. In the study, no questions were asked to reveal the identity of individuals and all the questions in the questionnaire were prepared in accordance with scientific sources. The purpose of the study was clearly stated in the questionnaire sent to the individuals and the participation was based on voluntariness.

\section{RESULTS}

In the scope of the research, descriptive statistics about the participants were conducted. Descriptive statistics of the participants are summarized in the table 1 ;

Table 1. Demographic Characteristics of Participants

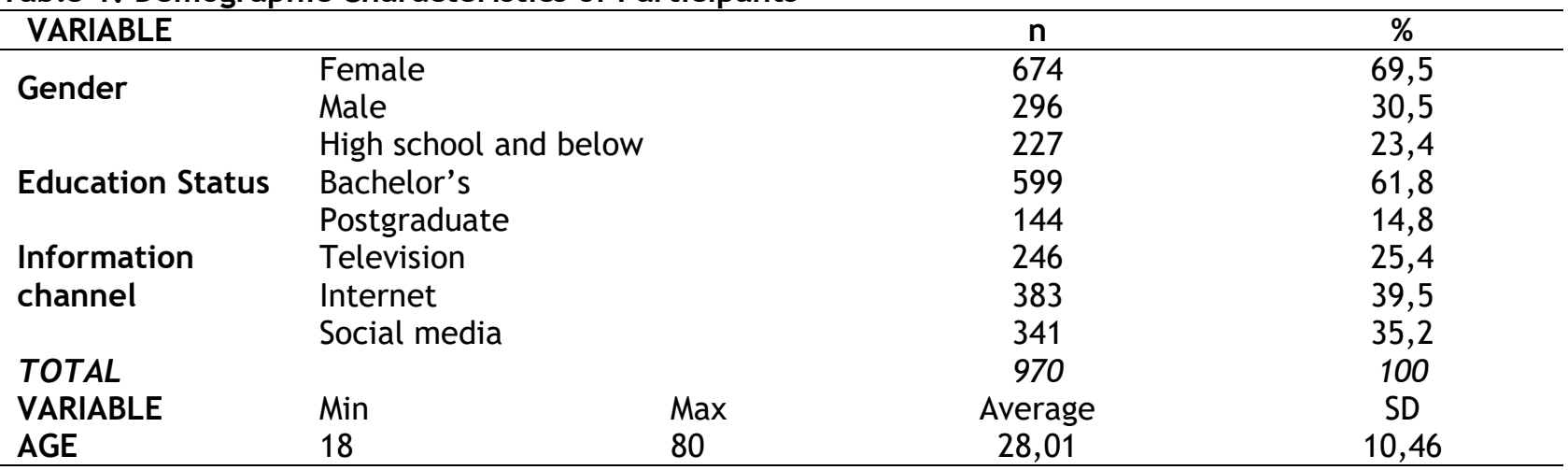

$69.5 \%$ of the respondents were women and $30.5 \%$ were men. $61.8 \%$ of them have bachelor's degrees, $23.4 \%$ have graduated from elementary, secondary and high schools and $14.8 \%$ have postgraduate degrees. $39.5 \%$ of the respondents stated that they obtained the information about the new coronavirus through the internet, 35.2\% obtained via social media and $25.4 \%$ via television. Following the descriptive statistics of the respondents, correct and incorrect answers given by the respondents to the questions and their lack of information about the questions were analyzed. The findings are summarized in the table below.

Respondents answered the propositions as yes, no or I don't know. While the answer yes is correct in some of the propositions, the answer no is correct in others. Within the scope of the study, the propositions to which the respondents gave the highest correct answers with a rate of $99.6 \%$ are the $21^{\text {st }}$ proposition "The elderly and those with chronic diseases are risky groups" and the $13^{\text {th }}$ proposition "Social isolation / quarantine is very important to prevent the spread of the new coronavirus". Therefore, the knowledge and awareness levels of the respondents about risky groups and the importance of social isolation in the new type of coronavirus outbreak were determined to be high. The proposition to which the least correct answers were given with a rate of $38.7 \%$ is the $19^{\text {th }}$ proposition "Even if we wash our hands with water and soap as recommended, we need to use disinfectant / cologne". It was determined that although the individuals wash their hands as suggested by the Ministry of Health, they thought that the necessary hygiene could not be provided in their hands, and that it is required to use cologne or disinfectant after washing. While $56.8 \%$ of the respondents answered this proposition incorrectly, $4.5 \%$ stated that they do not have any information. The average of correct answers given by the respondents to the 23rd propositions is $81 \%$. When the responses given were examined, it was seen that the general knowledge and awareness level of the society about the new type of coronavirus is high. However, the respondents gave relatively low 
correct answers to the second and third propositions regarding whether the new type of coronavirus can be transmitted sexually and by blood. It was determined that $45.5 \%$ of the respondents had wrong or no information that the new type of coronavirus is sexually transmitted, $43.6 \%$ of the respondents had wrong or no information that the new type of coronavirus is transmitted by blood. Likewise, $35.9 \%$ and $53.2 \%$ of the respondents answered incorrectly or stated that they do not have information related to the propositions about pet-to-human and human-topet transmission. On the other hand, $33.4 \%$ of the respondents answered incorrectly or stated that they do not know about the proposition that the new type of coronavirus may show no symptoms when it is transmitted to a person.

Table 2. Knowledge and Awareness Scores of COVID-19

\begin{tabular}{|c|c|c|c|c|}
\hline Questions & $\begin{array}{l}\text { Correct } \\
\text { answer }\end{array}$ & $\begin{array}{l}\text { Wrong } \\
\text { answer }\end{array}$ & Unknown & Total \\
\hline $\begin{array}{c}\text { 1-The new coronavirus is transmitted through } \\
\text { the respiratory tract. }\end{array}$ & $854(\% 88)$ & $95(\% 9,8)$ & $21(\% 2,2)$ & $\begin{array}{c}970 \\
(\% 100)\end{array}$ \\
\hline 2-The new coronavirus is transmitted sexually. & $529(\% 54,5)$ & $196(\% 20,2)$ & $245(\% 25,3)$ & $\begin{array}{c}970 \\
(\% 100)\end{array}$ \\
\hline $\begin{array}{l}\text { 3-The new coronavirus is transmitted through } \\
\text { the blood. }\end{array}$ & $547(56,4)$ & $188(\% 19,4)$ & $235(\% 24,2)$ & $\begin{array}{c}970 \\
(\% 100)\end{array}$ \\
\hline 4-We can snatch new coronavirus from pets. & $622(\% 64,1)$ & $151(\% 15,6)$ & $197(\% 20,3)$ & $\begin{array}{c}970 \\
(\% 100)\end{array}$ \\
\hline $\begin{array}{l}\text { 5-The new coronavirus can pass from humans } \\
\text { to pets. }\end{array}$ & $454(\% 46,8)$ & $207(\% 21,3)$ & $309(31,9)$ & $\begin{array}{c}970 \\
(\% 100)\end{array}$ \\
\hline $\begin{array}{l}\text { 6-Wearing a mask is the only way to be } \\
\text { protected against the new coronavirus. }\end{array}$ & $928(\% 95,7)$ & $28(\% 2,9)$ & $14(1,4)$ & $\begin{array}{c}970 \\
(\% 100)\end{array}$ \\
\hline $\begin{array}{l}\text { 7-As long as we wash our hands, the new } \\
\text { coronavirus does not infect us.* }\end{array}$ & $787(81,1)$ & $149(15,4)$ & $34(\% 3,5)$ & $\begin{array}{c}970 \\
(\% 100)\end{array}$ \\
\hline $\begin{array}{l}\text { 8-The new coronavirus is not different from the } \\
\qquad \text { flu.* }\end{array}$ & $743(76,6)$ & $170(\% 17,5)$ & $57(\% 5,9)$ & $\begin{array}{c}970 \\
(\% 100)\end{array}$ \\
\hline 9-Anyone caught in the new coronavirus dies. & $939(\% 96,8)$ & $11(\% 1,1)$ & $20(\% 2,1)$ & $\begin{array}{c}970 \\
(\% 100)\end{array}$ \\
\hline 10-Nobody caught in the new coronavirus dies. & $932(\% 96,1)$ & $8(\% 0,8)$ & $30(\% 3,1)$ & $\begin{array}{c}970 \\
(\% 100)\end{array}$ \\
\hline $\begin{array}{l}\text { 11-As long as my immune system is strong, I am } \\
\text { not likely to catch the new coronavirus* }\end{array}$ & $757(\% 78)$ & $148(\% 15,3)$ & $65(\% 6,7)$ & $\begin{array}{c}970 \\
(\% 100)\end{array}$ \\
\hline 12-The new coronavirus can infect anyone. & $914(\% 94,2)$ & $35(\% 3,6)$ & $21(\% 2,2)$ & $\begin{array}{c}970 \\
(\% 100)\end{array}$ \\
\hline $\begin{array}{c}\text { 13-Social isolation / quarantine is very } \\
\text { important to prevent the spread of the new } \\
\text { coronavirus. }\end{array}$ & 960 (\%99) & $1(\% 0,1)$ & $9(\% 0,9)$ & $\begin{array}{c}970 \\
(\% 100)\end{array}$ \\
\hline $\begin{array}{c}\text { 14-The new coronavirus can be transmitted by } \\
\text { placing hands on the eyes. }\end{array}$ & $836(\% 86,2)$ & $77(\% 7,9)$ & $57(\% 5,9)$ & $\begin{array}{c}970 \\
(\% 100)\end{array}$ \\
\hline $\begin{array}{l}15-\text { The new coronavirus can be spread by } \\
\text { placing the hands into the mouth and nose. }\end{array}$ & $946(\% 97,5)$ & $12(\% 1,2)$ & $12(\% 1,2)$ & $\begin{array}{c}970 \\
(\% 100)\end{array}$ \\
\hline $\begin{array}{c}\text { 16-When the new coronavirus infects a person, } \\
\text { it may show no symptoms (it may be } \\
\text { asymptomatic). }{ }^{*}\end{array}$ & $646(\% 66,6)$ & $181(\% 18,7)$ & $143(\% 14,7)$ & $\begin{array}{c}970 \\
(\% 100)\end{array}$ \\
\hline $\begin{array}{l}\text { 17-Washing clothes at } 60 \text { to } 90 \text { degrees is one } \\
\text { of the methods of protection. }\end{array}$ & $885(\% 91,2)$ & $26(\% 2,7)$ & $59(\% 6,1)$ & $\begin{array}{c}970 \\
(\% 100)\end{array}$ \\
\hline $\begin{array}{l}\text { 18-Washing hands with soap and water for at } \\
\text { least } 20 \text { seconds provides hand hygiene. }\end{array}$ & 951 (\%98) & $14(\% 1,4)$ & $5(\% 0,5)$ & $\begin{array}{c}970 \\
(\% 100)\end{array}$ \\
\hline $\begin{array}{c}\text { 19-Even if we wash our hands with soap and } \\
\text { water as recommended, we should use } \\
\text { disinfectant / cologne.* }\end{array}$ & $375(\% 38,7)$ & $551(\% 56,8)$ & $44(\% 4,5)$ & $\begin{array}{c}970 \\
(\% 100)\end{array}$ \\
\hline $\begin{array}{l}20-\text { Common use of personal belongings can } \\
\text { cause the transmission of the new coronavirus. }\end{array}$ & $953(98,2)$ & $6(\% 0,6)$ & $11(\% 1,1)$ & $\begin{array}{c}970 \\
(\% 100)\end{array}$ \\
\hline $\begin{array}{l}\text { 21-The elderly and those with chronic diseases } \\
\text { are risky groups. }\end{array}$ & $966(\% 99,6)$ & $1(\% 0,1)$ & $3(\% 0,3)$ & $\begin{array}{c}970 \\
(\% 100)\end{array}$ \\
\hline $\begin{array}{c}\text { 22- The incubation period of the new corona } \\
\text { virus is } 2-14 \text { days. }\end{array}$ & $930(\% 95,6)$ & $14(\% 1,4)$ & $26(\% 2,7)$ & $\begin{array}{c}970 \\
(\% 100)\end{array}$ \\
\hline $\begin{array}{c}\text { 23- There is a vaccine for the new coronavirus } \\
\text { and those who vaccinate do not get this } \\
\text { disease. }{ }^{*}\end{array}$ & $771(\% 79,5)$ & $27(\% 2,8)$ & 172 (\%17,7) & $\begin{array}{c}970 \\
(\% 100)\end{array}$ \\
\hline
\end{tabular}


Table 3. Overall Scores

\begin{tabular}{lcc}
\hline Dimensions & Overall Correct Scores & Status \\
\hline Knowledge Level & $90 \%$ & High \\
Awareness Level & $77 \%$ & High \\
Total & $81 \%$ & High \\
\hline
\end{tabular}

Knowledge and awareness level of people about COVID-19 is one of the main ways for protection. Therefore, we investigate the overall scores of knowledge and awareness. Overall knowledge and awareness level of the Turkish society were found to be high with $90 \%$ and $77 \%$ respectively. Total knowledge and awareness level was also high with $81 \%$.
After analyzing the general distribution and overall scores of the responses given, chi-square analysis was conducted to examine the relationship between the knowledge and awareness level regarding the new coronavirus and demographic factors such as gender, educational status and from which channel the information is obtained. The results of the analysis are summarized in the table 4;

Table 4: Results of Chi-Square Analysis

\begin{tabular}{cccccccccc}
\hline & \multicolumn{3}{c}{ Gender } & \multicolumn{9}{c}{ Education Status } & \multicolumn{3}{c}{ Information Channel } \\
\hline Questions & $\begin{array}{c}\text { Chi } \\
\text { square } \\
\left(\mathbf{X}^{2}\right)\end{array}$ & sd & Sig. $(\mathbf{p})$ & $\begin{array}{c}\text { Chi } \\
\text { square } \\
\left(\mathbf{X}^{2}\right)\end{array}$ & sd & Sig. $(\mathbf{p})$ & $\begin{array}{c}\text { Chi } \\
\text { square } \\
\left(\mathbf{X}^{2}\right)\end{array}$ & sd & Sig. (p) \\
\hline Q1 & 0,706 & 2 & 0,703 & 19,537 & 4 & 0,001 & 3,266 & 4 & 0,514 \\
Q2 & 1,156 & 2 & 0,561 & 21,413 & 4 & 0,000 & 4,261 & 4 & 0,372 \\
Q3 & 20,158 & 2 & 0,000 & 12,216 & 4 & 0,016 & 0,788 & 4 & 0,940 \\
Q4 & 10,066 & 2 & 0,007 & 30,722 & 4 & 0,000 & 11,767 & 4 & 0,019 \\
Q5 & 0,403 & 2 & 0,818 & 23,075 & 4 & 0,000 & 7,489 & 4 & 0,112 \\
Q6 & 1,065 & 2 & 0,587 & 25,279 & 4 & 0,000 & 9,761 & 4 & 0,045 \\
Q7 & 6,094 & 2 & 0,048 & 20,527 & 4 & 0,000 & 18,930 & 4 & 0,001 \\
Q8 & 0,849 & 2 & 0,654 & 52,857 & 4 & 0,000 & 4,439 & 4 & 0,350 \\
Q9 & 2,066 & 2 & 0,356 & 35,114 & 4 & 0,000 & 6,702 & 4 & 0,152 \\
Q10 & 0,306 & 2 & 0,858 & 24,206 & 4 & 0,000 & 3,728 & 4 & 0,444 \\
Q11 & 2,084 & 2 & 0,353 & 49,685 & 4 & 0,000 & 24,107 & 4 & 0,000 \\
Q12 & 1,949 & 2 & 0,377 & 22,112 & 4 & 0,000 & 2,273 & 4 & 0,686 \\
Q13 & 0,473 & 2 & 0,789 & 5,898 & 4 & 0,207 & 3,044 & 4 & 0,550 \\
Q14 & 0,600 & 2 & 0,741 & 18,089 & 4 & 0,001 & 5,284 & 4 & 0,259 \\
Q15 & 0,218 & 2 & 0,897 & 17,414 & 4 & 0,002 & 4,175 & 4 & 0,383 \\
Q16 & 6,801 & 2 & 0,033 & 73,568 & 4 & 0,000 & 23,478 & 4 & 0,000 \\
Q17 & 13,331 & 2 & 0,001 & 12,832 & 4 & 0,012 & 9,834 & 4 & 0,043 \\
Q18 & 1,242 & 2 & 0,537 & 5,417 & 4 & 0,247 & 7,809 & 4 & 0,099 \\
Q19 & 7,586 & 2 & 0,023 & 99,061 & 4 & 0,000 & 12,847 & 4 & 0,012 \\
Q20 & 5,634 & 2 & 0,060 & 13,783 & 4 & 0,008 & 11,772 & 4 & 0,019 \\
Q21 & 4,142 & 2 & 0,126 & 5,572 & 4 & 0,233 & 3,175 & 4 & 0,529 \\
Q22 & 0,234 & 2 & 0,889 & 17,790 & 4 & 0,001 & 5,995 & 4 & 0,200 \\
Q23 & 1,668 & 2 & 0,434 & 51,326 & 4 & 0,000 & 10,557 & 4 & 0,032 \\
\hline
\end{tabular}

As a result of the chi-square analysis, it was determined that knowledge and awareness scores significantly differed across gender especially with the propositions numbered $3,4,7,16,17$ and 19 ( $p<0.05)$. When the correct answer rates were analyzed, it was found that the knowledge and awareness level of women about new type of coronavirus was significantly higher than men. On the other hand, it was determined that there was a statistically significant discrepancy across the educational status according to all propositions except 13, 18 and 21 ( $p<0.05$ ). When the correct answer percentages were analyzed, it was determined that the groups with higher education gave significantly higher correct answers regarding the new type of coronavirus. It was determined that the propositions numbered 4,6 ,
7, 11, 16, 17, 19, 20 and 23 significantly differed across the information channels used by the respondents. $(p<0.05)$. In general, it was found that the percentage of respondents who obtained information via the internet channel was significantly higher than those using television and social media.

\section{DISCUSSION}

COVID-19 has spread worldwide since the day it was first identified and subsequently declared as an epidemic, and has been declared as "pandemic" by the World Health Organization. This shows that the pandemic has reached a level exceeding the continents. Therefore, COVID-19 has been seen in 213 countries / regions in total, 
more than 2.4 million people have been infected with the virus and about 170 thousand deaths have occurred. ${ }^{15}$ The total number of cases has been announced as 98.674 and the total number of deaths as 2.376 by the Ministry of Health in Turkey on April 22, 2020. ${ }^{16}$ However, as of April 10, 2020, Turkey is the ninth country having most cases. Thus, strict measures have been taken in Turkey as in other countries. Since the first case, information has been given about what the transmission routes are, and the ways of protection and especially the importance of social distance have been emphasized.

Countries are making great efforts to stop the spread of the virus worldwide. Various measures have been taken within the framework of these efforts. However, the success of these measures depends on many conditions. In addition to the health systems and capacities of countries, the overall economic situation determines the feasibility and success of the measures. Besides, the general level of knowledge regarding COVID19 is critical to implementing the measures and preventing infection. In this sense, it is important to raise the level of knowledge and awareness regarding the virus. In this study, the knowledge and awareness level of the society regarding COVID-19 were examined in line with the works of the Ministry of Health.

According to the results of this study, the knowledge and awareness level of the respondents regarding COVID-19 was found to be quite high with $81 \%$. The individuals had a high level of knowledge regarding the risky groups and the importance of social isolation. On the other hand, the level of knowledge about pet-to-human or human-to-pet transmission, probability of being asymptomatic, sexual or blood-borne transmission was not sufficient. In general, it was found that women, groups with higher education levels and those who use internet resources for information had significantly higher knowledge and awareness.

Although there are not enough studies in the literature related to COVID-19, the results of the studies have been started to be published. In parallel with this study, some of the studies have analyzed elements such as knowledge, awareness and attitude related to COVID-19.

In a study conducted in the UK and the United States, the knowledge and perception level of the public regarding COVID-19 was evaluated. According to the results of this study, which was included 3 thousand people from each country, $23.9 \%$ of Americans and $18.4 \%$ of the British think that the virus was produced as a biological weapon, and over $25 \%$ of both countries think that to avoid eating in Chinese restaurants may reduce the risk of infection. $29.7 \%$ of American respondents and $40.8 \%$ of British respondents believe that it is appropriate for an Uber driver to reject requests from people named East-Asia to reduce the risk of infection. Besides, 29\% of Americans and $24.4 \%$ of British believe that receiving a letter or package from China poses a risk of catching COVID-19. ${ }^{17}$ As it is seen, in this study, it was determined that there are many wrong perceptions about COVID-19. As a result of these perceptions, it is thought that the anxiety related to the virus may increase and various problems with racist origin may arise. Choosing the right information within information pollution is considered important.

According to the results of a study conducted to measure the awareness of healthcare professionals and healthcare students in the city of Mumbai and involving 1562 participants, 71.2\% of the respondents were answered the questionnaire correctly. While the medical faculty students had the highest correct response rate, the lowest correct answers were given by nonclinical/administrative staff. Fewer than half of the respondents could accurately identify close contact. More than three quarters of the respondents were aware of control methods such as rapid triage, respiratory hygiene, and proper isolation of the people considered to be infected. On the other hand, only $45.4 \%$ of the respondents were aware of the appropriate conditions for wearing masks and $52.5 \%$ were aware of hand hygiene. Based on the results of this study, it was stated that trainings on infection control should be provided in all healthcare professions. ${ }^{18}$

According to the results of a study conducted to determine COVID-19 awareness, knowledge, attitudes and related behaviors among US adults who are more vulnerable to COVID-19 due to age and comorbidity, $24.6 \%$ of the respondents have reported that they are very worried about COVID19 transmission. However, about a third of them failed to accurately express symptoms and ways to prevent infection. A quarter of respondents have reported that they are unlikely to become infected, while $21.9 \%$ have reported that the new virus have not affected their daily lives. Black respondents, those with an economic status below the poverty line and those with low health literacy had a lower level of anxiety about COVID-19. It was determined that many adults with accompanying health problems did not have critical information about COVID-19 and did not change their daily routines. It was stated in the study that more intensive public health efforts should be carried out for people with low level of knowledge. ${ }^{19}$

In a study involving 1,407 adult participants in Israel, the public's level of knowledge, perceived sensitivities, emotional reactions and behaviors about COVID-19 were examined. In this study, it was determined that women, elderly respondents, and respondents with higher level of knowledge and negative emotional responses about the virus had higher cautionary behavior. ${ }^{20}$ In a study examining the knowledge, attitudes and 
practices of healthcare professionals about COVID-19 in Henan Province, China, it was determined that $89 \%$ of the respondents had sufficient knowledge about COVID-19, 85\% were afraid of infection, and $89.7 \%$ were following the right practices. ${ }^{9}$ In another study conducted in China, the correct response rate about COVID-19 was found to be $90 \% .{ }^{9}$

In a study investigating the relationship between situational awareness and social isolation / distance, it was determined that social isolation is significantly affected by situational awareness. Therefore, it was stated that the use of official information sources could significantly increase awareness and adoption of protective measures in public health crises. ${ }^{21}$ In a study conducted in India, it was determined that the respondents had a medium level of knowledge about COVID-19 and sufficient knowledge about preventive practices. In the same study, the anxiety levels of the respondents were determined to be high, and more than $80 \%$ of the respondents were determined to have the need of a perceived mental health service. ${ }^{22}$ As it can be seen, the level of knowledge and awareness in general is high. In this study, it was determined that general level of knowledge and awareness was quite high (81\%). However, it should be noted that COVID-19 is a virus with a high transmission rate. Therefore, although the role of the groups with a high-level of knowledge is high in the prevention of the pandemic, the negativities created by the groups with a low-level of knowledge can reduce the success of efforts to stop the pandemic.

\section{CONCLUSION}

In conclusion, the study revealed that knowledge and awareness levels of men, people with low education level and the respondents who prefer television as a channel of information were low compared to other groups. Therefore, awareness raising activities should be increased especially for these groups. In addition, it is suggested that only official statements of authorized persons should be included in these channels in order to prevent misunderstandings and information pollution that may occur through social media and television.

\section{LIMITATIONS}

Due to the extraordinary situation, the first limitation of the study is related to sample which consists of 970 respondents who could be reached online and volunteer to participate. During the research process, related literature was limited with studies in Turkish and English. The study was limited to the quickly developed questionnaire to collect data and the responses given to this questionnaire. The questionnaire should have been developed by multidimensional steps and focus groups integration. However, it was not suitable due to the lockdown in Turkey. The sample size included in the study provides the external validity of the study, but anyone should act with deliberation on making a generalization on a national scale.

\section{ACKNOWLEDGMENTS}

The author would like to thank all participants to make this study possible.

\section{REFERENCES}

1. WHO. Coronavirüs, recieved from:. Available at: https: / /www.who.int/healthtopics/coronavirus\#tab=tab_1.

2. Heymann DL, Shindo N, Bedford J, et al. COVID-19: what is next for public health? Lancet. Feb 22 2020;395(10224):542-545.

3. İmai N, Dorigatti I, Cori A, Riley S, Neil MF. Estimating the potential total number of novel Coronavirus cases in Wuhan City, China. Imperial College London. ; 2020.

4. WHO. Coronavirus disease 2019 (COVID19) Situation Report -49. Available at: https://apps.who.int/iris/bitstream/han dle/10665/331449/nCoVsitrep09Mar2020eng.pdf. .

5. CDC. 2019 Novel Coronavirus. Prevention and Treatment. Cent. Disease Control Prev. 2020.

6. del Rio C, Malani PN. COVID-19-New Insights on a Rapidly Changing Epidemic. JAMA. 2020;323(14):1339-1340.

7. Ministry of Health. Available at: https://covid19bilgi.saglik.gov.tr/tr/; .

8. Ministry of Health. Available at: https://covid19bilgi.saglik.gov.tr/tr/covi d-19-yeni-koronavirus-hastaligi-nayakalanmamak-i-cin-oneriler; .

9. Zhong $B-L$, Luo $W, L i \quad H-M$, et al. Knowledge, attitudes, and practices towards COVID-19 among Chinese residents during the rapid rise period of the COVID-19 outbreak: a quick online cross-sectional survey. International Journal of Biological Sciences. 2020;16(10):1745-1752.

10. Geldsetzer P. Knowledge and Perceptions of COVID-19 Among the General Public in the United States and the United Kingdom: A Cross-sectional Online Survey. Annals of Internal Medicine. 2020.

11. Qian M, Wu Q, Wu P, et al. Psychological responses, behavioral changes and public perceptions during the early phase of the COVID-19 outbreak in China: a population 
based cross-sectional survey. 2020:2020.2002.2018.20024448.

12. Wang C, Pan R, Wan X, et al. Immediate Psychological Responses and Associated Factors during the Initial Stage of the 2019 Coronavirus Disease (COVID-19) Epidemic among the General Population in China. International journal of environmental research and public health.02/14/received02/28/revised03/ $03 /$ accepted $3 / 12 /$ entrez 3/12/pubmed3/19/medline 2020;17(5).

13. WHO. Available at: https: / /www.who.int/emergencies/dise ases/novel-coronavirus-2019/advice-forpublic.

14. Crosby RA, Salazar LF. Essentials of Public Health Research Methods: Burlington, MA : Jones \& Bartlett Learning; 2021.

15. WHO. Available at: https://www.who.int/emergencies/dise ases/novel-coronavirus-2019/advice-forpublic.

16. Ministry of Health. Available at: https://covid19.saglik.gov.tr/,.

17. Mathias J. Knowledge, perceptions of COVID-19 among the general public in US, UK. Available at: Accessed online: https: / /www.ormanager.com/briefs/kno wledge-perceptions-of-covid-19-amongthe-general-public-in-us-uk/.

18. Modi PD, Nair G, Uppe A, et al. COVID-19 Awareness Among Healthcare Students and Professionals in Mumbai Metropolitan Region: A Questionnaire-Based Survey. . Cureus. 2020;12(4):7514.

19. Wolf MS, Serper M, Opsasnick L, et al. Awareness, Attitudes, and Actions Related to COVID-19 Among Adults With Chronic Conditions at the Onset of the U.S. Outbreak: A Cross-sectional Survey. Annals of Internal Medicine. 2020.

20. Shiman-Altman S, Levkovich I. COVID-19 precautionary behavior: The Israeli case in the initial stage of the outbreak. BMC Public Health. 2020.

21. Qazi A, Qazi J, Naaseer K, et al. Analyzing Situational Awareness through Public Opinion to Predict Adoption of Social Distancing Amid Pandemic COVID-19. J Med Virol. 2020:1-7.

22. Roy D, Tripathy S, Kar SK, Sharma N, Verma SK, Kaushal V. Study of knowledge, attitude, anxiety \& perceived mental healthcare need in Indian population during COVID-19 pandemic. Asian Journal of Psychiatry. 2020/06/01/ 2020;51:102083. 